\title{
Community health: the risks of confusion and complacency
}

\author{
J Popay
}

It was Richard Titmuss, a British social historian and social scientist, who commented on the important link between confusion and complacency in health policy in a paper he wrote on community care in $1961 .^{1} \mathrm{I}$ am going to comment on the risks of confusion and complacency in relation to key issues within the field of community health.

Firstly, I want to talk about the phrase "community health" itself. Although it is a phrase which appeals to us for many reasons, I will argue that the related notions of public health and primary care may reduce confusion as we think about the nature of the task ahead and those who should be involved. Secondly, I want to consider briefly the social context for policy and practice in the domain of community health, Thirdly, I will suggest that there is confusion about the knowledge base that should be informing developments in these areas. I will argue that lay expertise about health and illness is a vital but neglected component of this knowledge base. Fourthly, I want to highlight some recent additions to the potential areas of confusion and complacency which stem from organisational changes within primary care. Finally, I shall highlight some of the central issues that I believe are in danger of being neglected among all the possible confusion.

This panoramic approach will inevitably over simplify matters of detail. However, I hope it will contribute to the developing agenda for health policy and practice in the future.

\section{The meaning of community health}

The phrase "community health" links two of the most problematic words in the social sciences. Both carry a considerable emotional and ideological load. I will focus on two related uses of the phrase. Firstly, it is frequently used to mean the "health of a population". The problem here, of course, is that the word community does not simply denote a population. It has other connotations. It is the memory of a bygone age, when small groups of people shared a common identity, living together with a sense of neighbourliness and providing mutual aid and support in times of need. This idea of community is depicted in some of Lowry's paintings around this area of the country. There is, of course, little evidence that this ideal community ever really existed - any more than it does today - and Lowry also reminds us of the darker side of social life in many paintings depicting poverty and discontent.

While community conjures up ideas about concensus and equality - the issues at the centre of debates about public life are about dissent and inequality. ${ }^{2}$ This is none the less the case in the health field. As I will show later, the major health problems facing us today are partly the product of inequality and require dissent The task involved is therefore more accurately reflected in the phrase public health rather than community health. Though the phrase may still need to be finally liberated from its status as a colony of medicine - it makes it clear that we are talking about populations and not individuals and that these populations may have conflicting interests and identities. The word "public" also carries ideological baggage. However, the association of the word public with collective concern and ownership seems appropriate for the health problems that need to be addressed.

The second use of the phrase community health that I wish to draw attention to is found in the label "community health services". Intuitively perhaps, we all know what we mean by community health services - at least within particular counties. But beyond specific examples such as health visitors, it is far from clear what is meant by the term. In the UK, many would point to community health trusts or community units within combined trusts and say that is what they are. But for many people this is too narrow a definition. It excludes professionals who work largely in the "community" but may in some areas be based in hospitals - such as midwives and physiotherapists. In Britain, at least, it also excludes those providing care through the family health services authorities - GPs, pharmacists, opticians and dentists, podiatrists, practice nurses, and nurse facilitators. Primary health care might be a better phrase to refer to that which we all know to be important but cannot quite define. But even this has problems: much primary care (in the sense of first contact care) goes on within hospital accident and emergency departments and what about social care? And what about all those lay people - women and less frequently men - who provide the overwhelming bulk of health care in "the community" as partners, parents, relatives, neighbours, and friends? ? $^{3}$

Some commentators have attempted to define primary care in terms of what it is not rather than what it is. Pat Gordon of the King's 
Fund Centre argues that it is not institutionally based - it can go on anywhere - and that it is not "not specialist". ${ }^{4}$ A great deal of primary care is specialist care. She suggests that one way forward is to begin to list the distinguishing characteristics of a primary care service to help reach locally negotiated working definitions. Her list is shown in table 1.

Table 1 Distinguishing characteristics of primary care

- First contact care

- Accessible care

- Comprehensive care

- Continuing care

- Co-ordinated care

- Delivered by generalists

- A network of services

We each have our own particular views about the contents of any list of distinguishing characteristics for primary care. But we do need to have greater clarity and precision. This is highlighted by the quote from Richard Titmuss that I alluded to at the start of the lecture:

"Confusion has often been the mother of complacency. In the public mind the aspirations of reformers are transmuted by the touch of a phrase, into hard won reality. What some hope will one day exist is suddenly thought by many to exist already. All kinds of wild and unlovely weeds are changed, by statutory magic and comforting appellations, into the most attractive flowers that bloom not just in the spring but all the year round..."

"And what of the everlasting cottage garden trailer 'community care'? Does it not conjure up a sense of warmth and human kindness, essentially personal and comforting, as loving as the wild flowers so enchantingly described by Lawrence in Lady Chatterley's Lover?"s

Titmuss himself did not provide any precise definition of community care. I am not about to offer any simple definitions of community health or public health, community health care or primary care. But I am arguing that if those involved in the NHS locally and nationally do not seek greater clarity about what is being pursued in health and in health care terms then we may well find that "what some hope will one day exist may suddenly be thought by many to exist already". The complacency this may create will make the job of those seeking change all the more difficult.

There are at least three areas in which I feel the scope for greater clarity is still considerable. These are: the social context for public health and primary care; the status of lay knowledge within the health field; and the notion of a primary care led NHS.

\section{The social context for public health and primary care}

There are two key aspects of the social context for public health and primary care: the changing nature of health problems in the population and the persistence of social inequalities in the experience of health and illness.

Some aspects of the changing health problems of the late 20th century have been well documented. All health professionals are fa-

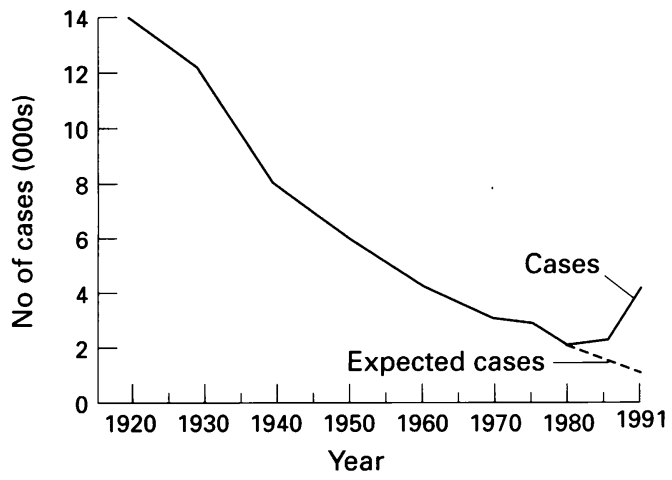

Figure 1 Cases of tuberculosis in New York City 1920-91 (Source, ref ${ }^{9}$ ).

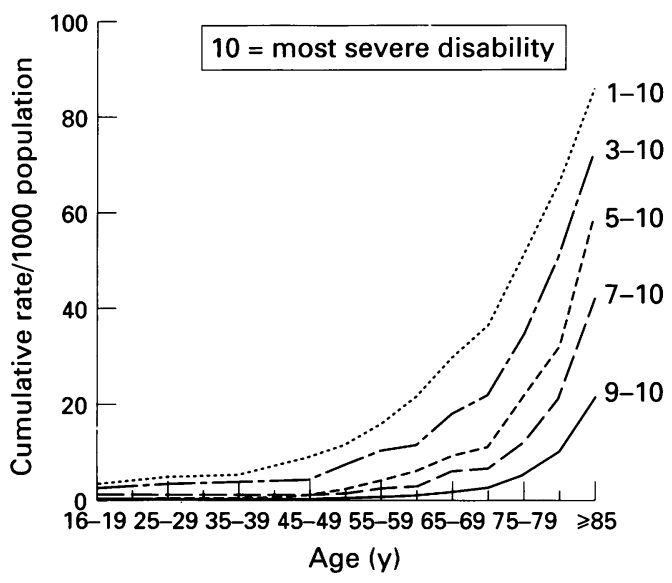

Figure 2 Disability in relation to age (source, ref ${ }^{10}$ ).

miliar with the decline in the major infectious disease killers of the last century. ${ }^{67}$ What is perhaps less widely appreciated is the return of infectious diseases as a major health problem (notably AIDS/HIV and tuberculosis). ${ }^{8}$ There is evidence, for example, that since 1985 the long term downward trend in TB has been reversed, even in cities in western industrialised countries, as figure 1 shows. ${ }^{9}$

Another aspect of the changing nature of health problems facing those within primary care is the increasing significance of chronic illness and disability. Figure 2 illustrates the close link between disability and age, showing the cumulative rate of disability of varying severity with age. Over 40 people per 1000 aged over 70 experience some degree of disability and it is noteworthy that although severe disability is concentrated among the elderly, the prevalence of mild to moderate disability begins to increase noticeably around the age of 50 , when people might be facing another 25 years of life ${ }^{10}$ It is, of course, important to stress that disability is frequently the result of social and environmental factors. In theory these are amenable to change as a result of health and social care interventions. An issue that I return to later.

The second dimension of the social context for public and primary care that I wish to highlight is the social patterning of the experience of ill health. The continued existence of inequalities in health despite the welfare state were brought to the forefront of public debate by the Black report, published as we all know 
Deaths

Adult deaths, $1979-80,1982-83$

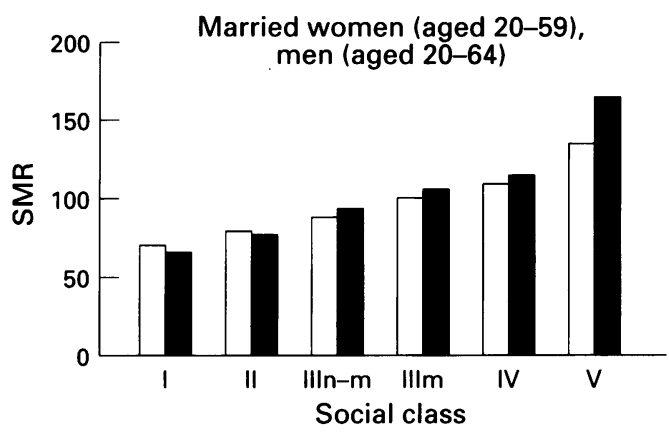

Source: Occupational Mortality, OPCS (1986) $)^{13}$

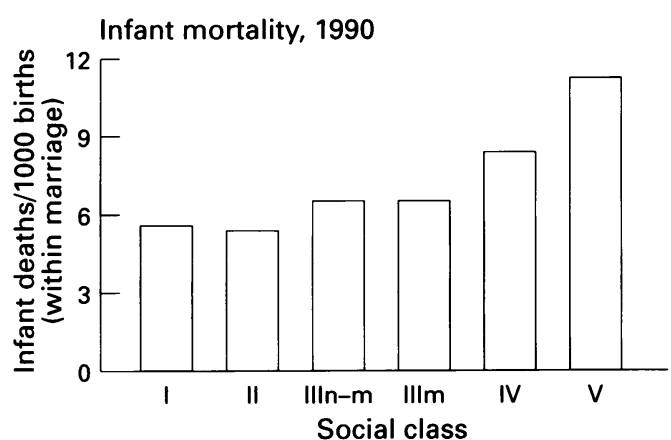

Source: Mortality Statistics, OPCS (1992) ${ }^{15}$

\section{IIIness}

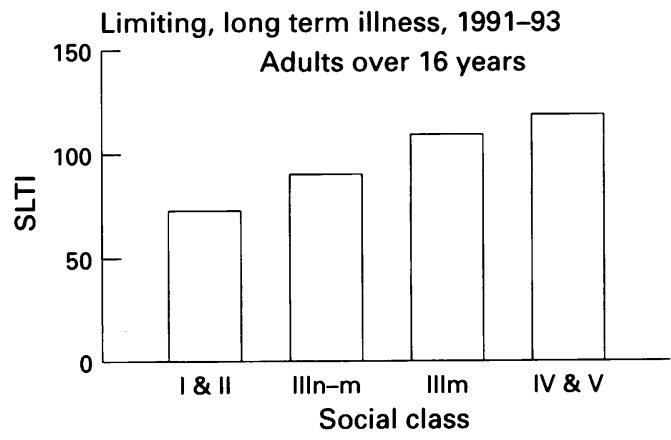

Source: King's Fund Institute's analysis of OPCS Omnibus Survey"
Other socioeconomic indicators and death, 1976-81

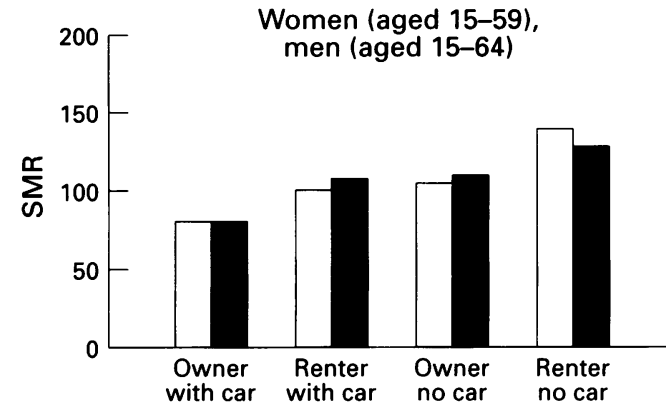

Source: OPCS Longitudinal Study, Goldblatt $(1990)^{14}$

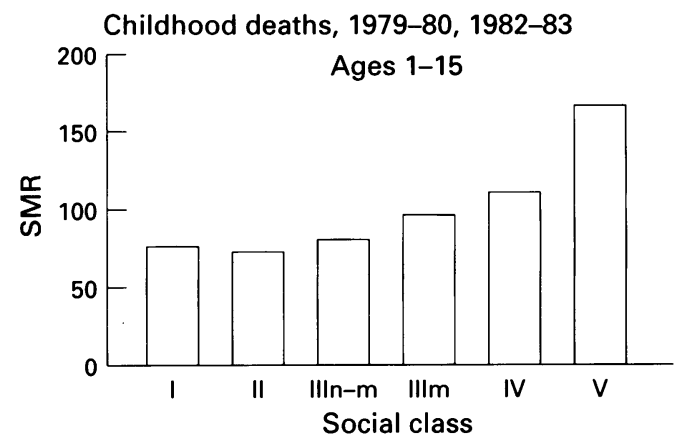

Source: Occupational Mortality, OPCS (1988) ${ }^{16}$

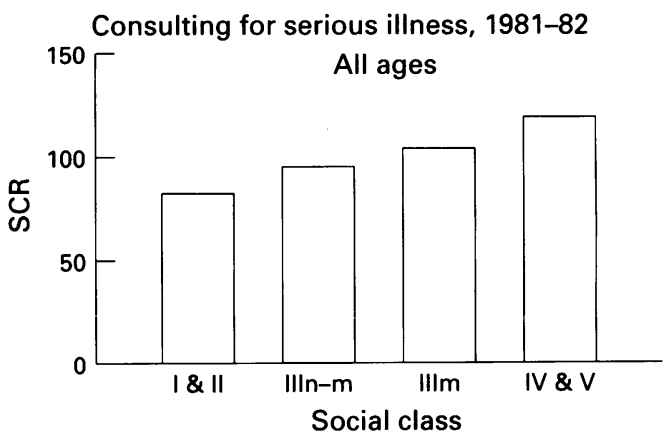

Source: GP Morbidity Survey, McCormick and Rosenbaum (1990) ${ }^{18}$

Figure 3 Standardised mortality ratios in relation to social class and age group (source ref ${ }^{17}$ ).

in a somewhat ineffective way in 1980 and later by Penguin. ${ }^{112}$ Since then data such as those in figure 3 showing the wretched predictability of the gradient in standardised mortality ratios between people in different socioeconomic circumstances have become familiar to us all. ${ }^{13-18}$ Gradients in mortality rates between the better and worse off are only one indicator of the nature and scale of inequalities in health and illness in our society. Similar inequalities exist in expectation of life at different ages, in the risk of injury, in reported symptoms, in the experience of disability, and in poor subjective perceptions of health. ${ }^{1920}$ These variations are inequalities because they represent differences which are unacceptable and avoidable.

It is perhaps inaccurate to suggest that there is a degree of complacency around in the face of such inequalities. Perhaps it is better described as powerlessness. Whatever the case, inequalities in health failed to be incorporated as a priority for policy and practice in the Chief Medical Officer's Health of the Nation initiative, though there is now a subgroup considering ways of reducing social variations in health. The question of equity frequently figures in the preamble to the many annual purchasing plans and business plans that now adorn NHS bookshelves. But examples of innovative and brave initiatives to address the issues involved are still the exception. Meanwhile, evidence is accumulating that these inequalities are growing.

For example, Peter Phillimore and his colleagues at the University of Newcastle have looked at the standardised mortality ratios in different areas in the north east of England. ${ }^{21}$ Electoral wards were ranked according to an index of deprivation derived from census data for 1981 and 1991. Although the mortality experience in all wards improved over the 


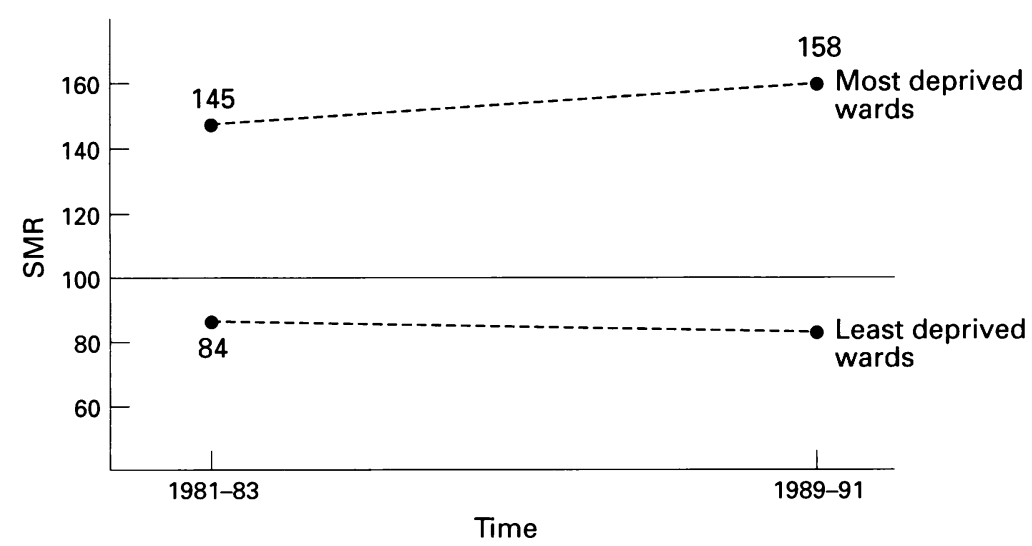

Ratio of most deprived to least deprived wards: 1981-83 1.73

$1989-91 \quad 1.95$

Figure 4 Growing gap in mortality ratios between the poorest and wealthiest electoral wards in the north east of England (source ref ${ }^{21}$ ).

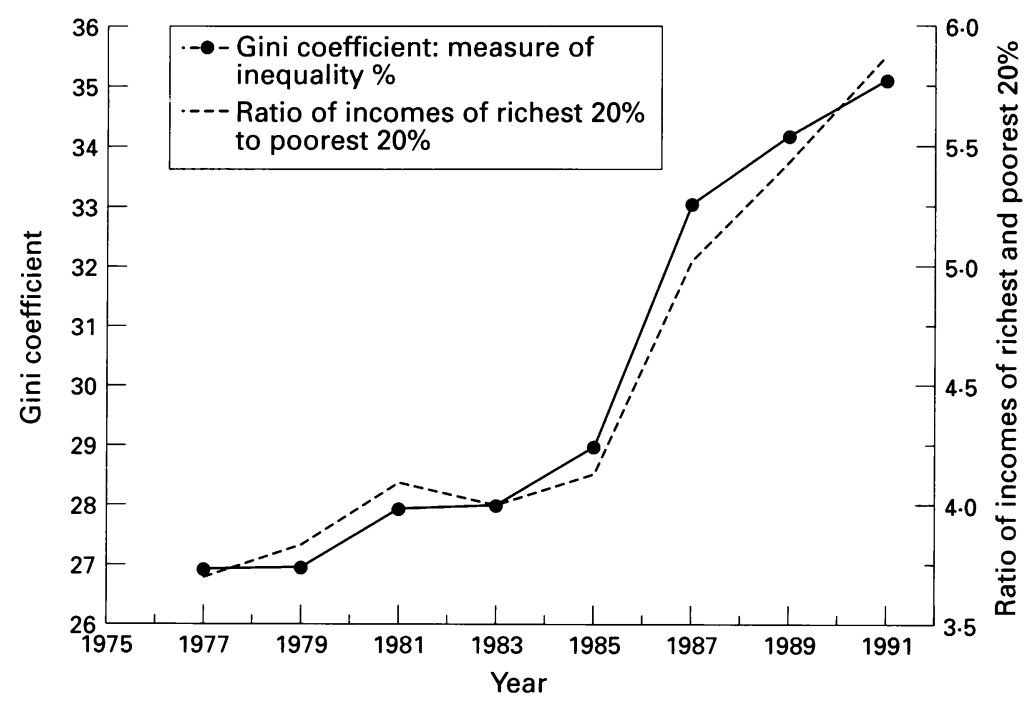

Figure 5 Inequalities in income (source ref ${ }^{22}$ ).

period, that for the poorest wards improved less slowly. For some groups of people in some of the poorest wards (for example, for men aged between 15 and 44 women aged 65 to 74) mortality actually increased over the period. This led to a growing gap in the mortality experience of the poorest and the wealthiest wards from $73 \%$ in $1981-3$ to $95 \%$ in $1989-91$, as figure 4 illustrates. The causes of these inequalities in health are the focus of much debate, often acrimonious, amongst academics, health professionals, and politicians. Inside all the hot air three things are patently obvious. Firstly, there is no simple unicausal explanation. Secondly, we are not talking only about the health of the poorest but rather a continuous gradient between different social groups such that improvements will mean gains in terms of life expectancy, for all social groups. Thirdly, inequalities in health are inextricably linked to inequalities in wealth - to the material circumstances in which people live and which shape the choices they make about their lives and those of their children. Over the period that inequalities in health in Newcastle have widened, so, as figure 5 shows, inequalities in income have similarly grown. ${ }^{22}$

There is much to play for here in terms of health gain and economic savings if we can reduce inequalities in health by improving the health of the less advantaged in society. But what can primary care do? Is this not all a question of the distribution of income and wealth and anti-poverty strategies? I would suggest that while health care systems in general and primary care in particular may only be able to have a small impact on these patterns this is none the less important. It may be vital in the lives of individuals.

At the level of policy, resources can be more effectively targeted at areas of greatest needs. The services delivered can be subjected to what has been termed an "equity audit". ${ }^{23}$ This would assess the extent to which they are accessible and appropriate for those who need them most. In this context, it is worth noting that the Chief Medical Officer's subgroup on social variations in health has commissioned a review by the centre for reviews and dissemination at the University of York. They are identifying relevant effective interventions which could be implemented by the NHS alone or with others to reduce these social variations in health. Though the report should be published shortly, pressure from the field might speed this process up!!

At the level of both individual practice and policy it makes no sense to blame the victims of poverty and disadvantage for the effects on their health and that of their children. Attempts to change health damaging behaviour need to take account of the structural determinants of such behaviour - financial worries, social isolation, and poor housing - if they are to be effective. This position has been well developed by Hilary Graham and Clare Blackburn in relation to smoking prevention initiatives. ${ }^{24} \mathrm{It}$ has also been recognised in many initiatives within the voluntary or self help sectors. ${ }^{2526}$

\section{The status of lay knowledge}

This leads into the second area of confusion and complacency on which I wish to comment: the status of lay knowledge about health, illness, and health care. In seeking to understand why poor women smoke in full knowledge of the dangers to their own health and that of their children, Graham listened to what women themselves had to say. ${ }^{27}$ In contrast, well intentioned practice among health professionals aimed at improving the health of people living in poverty often fails to take account of the views of the people involved. The rising popularity of projects to enhance the parenting skills of women living in poverty is a good example. ${ }^{28}$ While poor women may well appreciate support dealing with children in poor social and material circumstances, these projects frequently fail to ask women what their priorities are before wading in with advice on parenting skills.

The central problem here is that different types of knowledge have different status within society in general and within health care sys- 


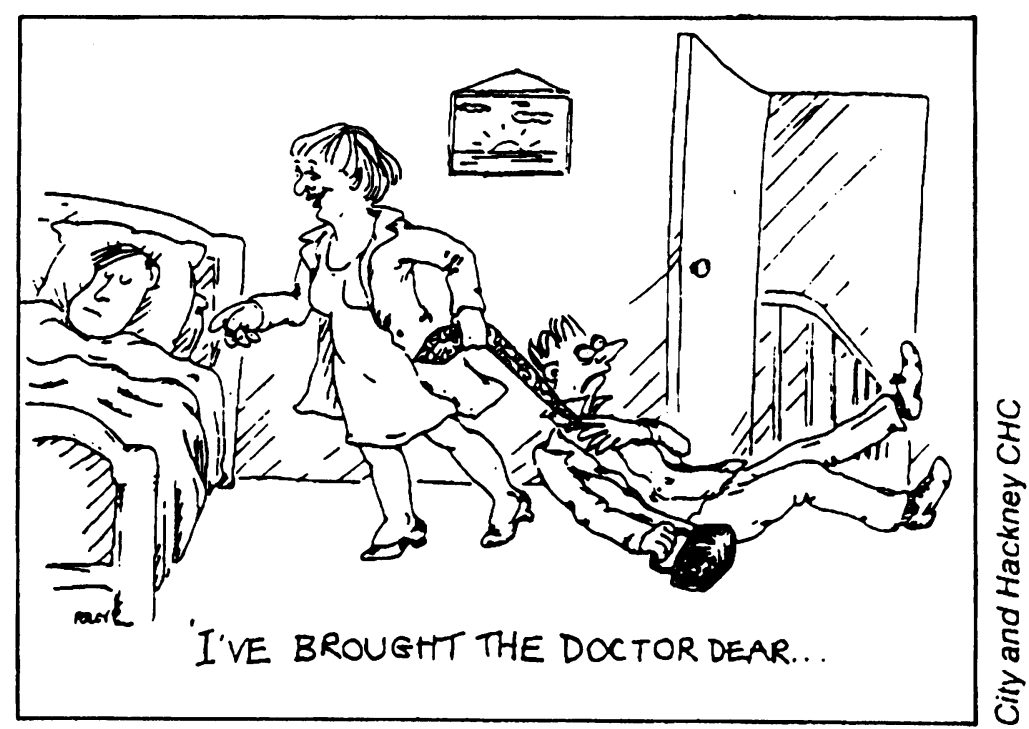

Figure 6 his many medical encounters set up, so I believed, to review Tom's situation in the light of a series of what appeared to be mild fits, the consultant physician began our consultation with the following comments:

"Well, Tom's chest is being dealt with by your GP, his heart by the chaps in Liverpool, so everything is alright on those fronts - you have come to me about his funny turns - yes?"

Stuck for words, my attention was directed towards a loud bang in the corner of the office where Tom had managed to knock down a very full file. Papers were now scattered across the floor.

"No", I said, "I thought I was coming to talk to you about that small person who is causing havoc over there". Though a little irritated by my remark and my son's unruly behaviour the man continued with his line of enquiry, arranged an EEG for Tom, and we returned home. I did not take Tom for the EEG and stopped the antihistamines that I believed to be causing the fits. They duly stopped. Unfortunately, Tom's encounters with the medical men continue ...

tems in particular, and lay knowledge - that is, the knowledge all of us acquire as a result of our daily experiences of life, disease, illness, and death - is awarded the lowest status of all. Additionally, even within lay knowledge, there is a hierarchy, with the knowledge of some groups of lay people (notably women and people from minority ethnic groups) being given less value than others. ${ }^{29}$

The importance of basing decision making about policy and practice on knowledge has been highlighted by Professor Michael Peckham and his colleagues within the NHS R\&D strategy. This has created a considerable agenda for primary care, one of the most pressing issues being to consider existing evidence on the effectiveness of what is done and to evaluate that which has not yet been evaluated. This will require new skills and new ways of working among health professionals. But surely the first question to ask is: whose knowledge is to count in this knowledge based world?

Despite the rhetoric of consumer oriented healthcare and multi-professional care, the old adage "doctor knows best" still reflects reality to a considerable extent. Medical knowledge takes precedence. I do not mean the knowledge of individual doctors, though it can often feel like this to patients. I am referring to the knowledge generated by a biomedical approach to research and practice, popularly termed "scientific knowledge". It is not appropriate for me to consider this topic in detail here. Suffice it to say that the biomedical approach to knowledge can be characterised as focusing on the identification and treatment of specific diseases and involves the atomization of the body into its component parts. It also involves a particular approach to the generation of what is taken to be legitimate knowledge - that is, to the research process.

A personal anecdote may serve to illustrate the point about the nature of biomedical knowledge.

The health career of my 6 year old son Tom has provided rich pickings and much anxiety for his medical sociologist mother. At one of
The dominance of biomedical knowledge can cause difficulties for other health professionals. Many accept the biomedical approach to research and practice and are trained into this way of thinking. But their experience of providing care frequently introduces a somewhat different understanding of the health problems their patients have. Yet in their encounters with medicine, this experiential and professional knowledge may be devalued or discounted.

Reassuringly for some within the health field, lay people are increasingly challenging the biomedical perspective and professional expertise. Though perhaps not quite so literally as the lady in the cartoon in figure 6 who "has brought the doctor dear". This challenge is perhaps most evident in the growing number of instances of what has been termed "popular epidemiology". That is, situations where local residents have taken action on an environmental hazard which they believe to be damaging to their health but they feel is being ignored or discounted by professional experts. In this country, such actions have focused on issues such as pollution of water supply or the atmosphere, heavy traffic, and damp housing. ${ }^{30}$ In the last case, for instance, residents of a Glasgow housing estate asked university academics to undertake research into their "belief" that the damp in their homes (rather than their smoking) was causing respiratory problems in their children - a lay belief subsequently supported by the research published by the $B M \mathcal{F} .^{31}$

Within the NHS the views of lay people are increasingly being sought on a range of issues including health needs, ways of meeting these needs, and the quality of services - including the outcomes of care. So much so, in fact, that consultation fatigue may be setting in on both sides.

However, while initiatives to involve lay people in the NHS are to be welcomed it is not always clear that those seeking lay views are prepared for the type of information they will receive. Nor is it the case that these views will be given equal status to those of the pro- 


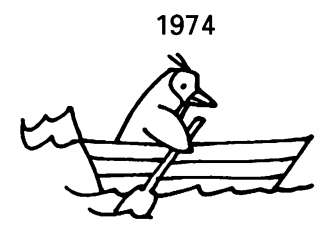

1980

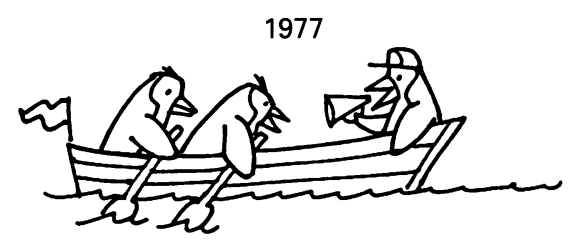

1985
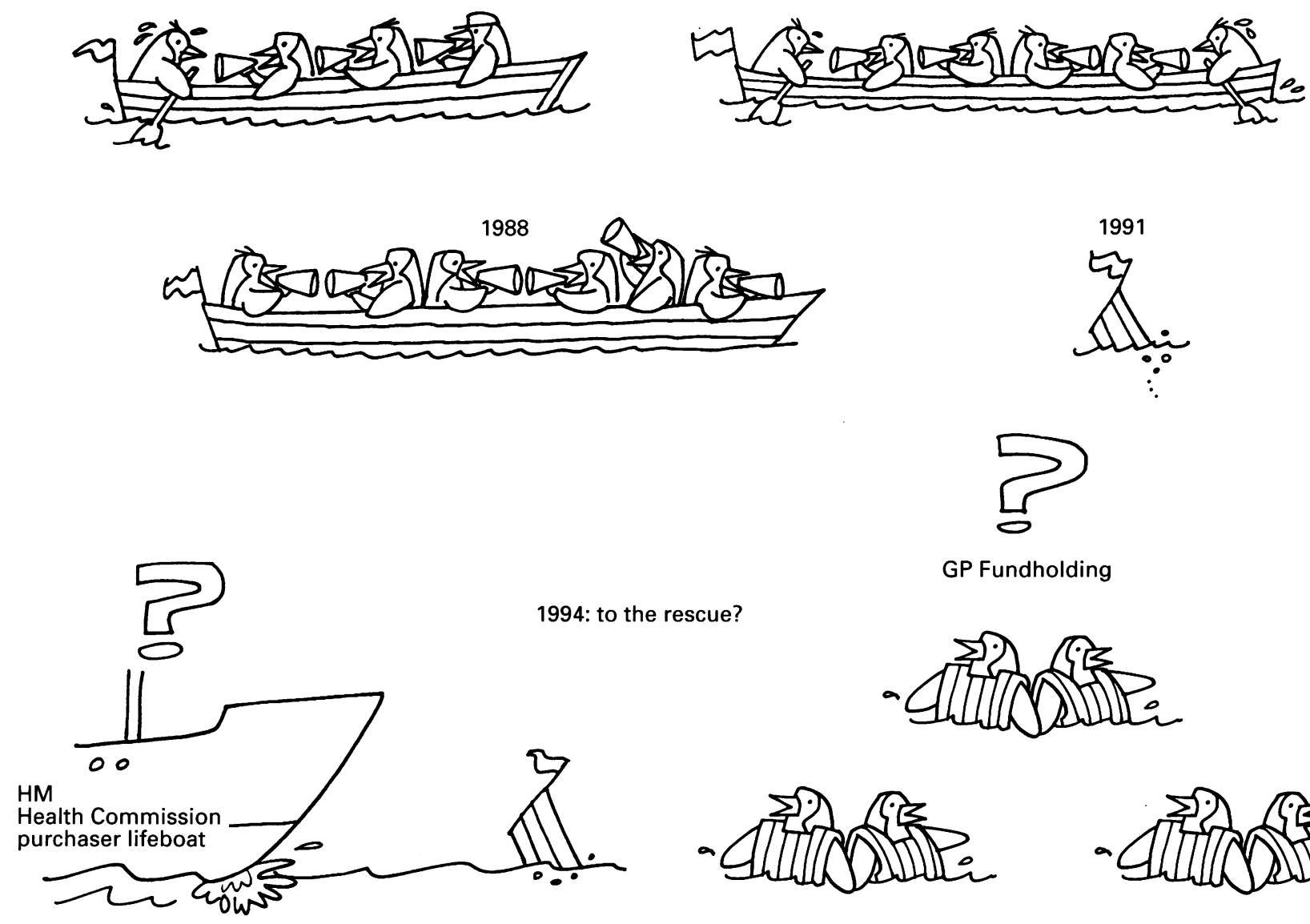

GP Fundholding

94: to the rescue?
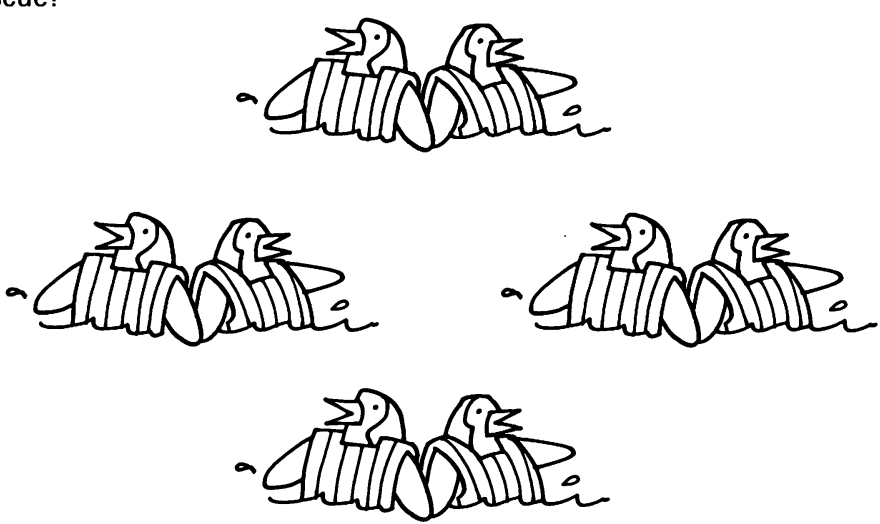

lifebelts inc

Figure 7 A potted history of the NHS (source, Royal College of Radiologists Newsletter-amended).

fessionals or of epidemiological research within any decision making process.

As already illustrated, lay experts can help us to understand better the factors shaping health damaging behaviour. They can spot the iatrogenic effects of drugs before the professionals and they, not us, are the experts on the problems they have..$^{29}$ Moreover, their views about their health seem to have significant predictive power. There is evidence that people who report poor health, despite an absence of any obvious pathology, have an increased risk of mortality in subsequent years. ${ }^{32}$

Listening to what people have to say poses considerable challenges for the NHS. At the moment the preoccupation seems to be with how to get these views. Much more important than how to get lay views, however, is what status is given to the views once they have been obtained and how to deal with the difficulties that genuinely listening to lay people will inevitably create within any health care system.

There is, for example, unlikely to be a consensus view from the public - different groups may have different views (just as different professional groups have different views). Lay people will frequently go beyond the traditional boundaries of health care (complaining, for example, that the removal of rats and rubbish is their top health priority). They may disagree with clinical and professional perspectives on need and on the most appropriate way of meeting need. They may even misunderstand and need more information.

However, it is not appropriate to respond to these differences by arguing that the public are ignorant. There is a need for mutual respect for the knowledge both lay people and professionals have, a need for recognition of the constraints within which both the NHS and 
lay people operate, and a need for an ongoing dialogue. But the outcome of this dialogue must include the possibility for learning on both sides, and allow the possibility that the lay view is right.

\section{A primary care led NHS}

And so to the last area of confusion. Foreign commentators on the UK health care system have often expressed surprise at the frequency of organisational change within the NHS - if there is a problem, so received wisdom seems to go, change the structure. In the past two decades the NHS has undergone three major reorganisations and many more minor ones as part of a more general epidemic of reforms. However the changes heralded by the publication of Working for Patients and Caring for People in 1989 and introduced in 1990 with the new GP contract, in 1991 with the beginning of the purchaser provider split and the first wave of GP fundholding, and in 1993 with the implementation of Caring for People, are the most far reaching since the NHS was created in 1946.

The reforms have ardent critics and advocates and feelings run high on both sides of the debate. There are also many people (among whom I include myself) who acknowledge that some of the changes have been for the good but are truly concerned about the future of the NHS. The most pessimistic scenario is amusingly captured in figure 7 . Here we see the NHS finally crumbling in 1991 under the weight of competing demands from politicians and various stakeholders within the service. The last scene, however, sees the arrival of the purchasing authority lifeboat to the left and a flotilla of GP fundholding lifebelts to the right (no political significance here). The shape the NHS is in when or if it is rescued seems to depend on the final balance of power between the two groups of rescuers!

A prominent aspect of the most recent reforms has been that for the first time since 1946 primary health care has been placed centre stage. There are, of course, a number of reasons for this - not always compatible with each other. Some are shown in table 2.

Table 2 Reasons for the importance of primary care

- Cost containment

- Efficiency/effectiveness

- Standards of care

- Coordination

- Unmet needs

- Inappropriate demand

There are many issues subsumed by these headings. They include, for example, concerns over the cost of GP prescribing and gross variation in referral rates; concern over the poor quality of practice premises and of the clinical care provided, (often poorest in areas where needs are greatest); and concern over the lack of coordination between GPs and hospitals, between GPs and other health professionals, and between health and social care. There is also concern about the inappropriate nature of "family health care" for certain groups such as students, commuters, the homeless, or young people seeking family planning advice; concern about the extent of unmet needs particularly among people with chronic illness and their carers; and concern about demands for care out of hours or the use of accident and emergency, which may be arrogantly labelled as "inappropriate demand".

Many initiatives have been put in place to address these issues by health care providers and by district health authority and family health services authority staff. Additionally, some community trusts are developing an imaginative home care agenda for themselves. As Gordon has argued, their capacity to provide safe, high quality intensive nursing care at home will determine the shift in services from hospital to community. ${ }^{33}$ The GP contract has encouraged more attention to the care of people with particular chronic conditions, notably asthma and diabetes, and to the prevention of illness, notably coronary heart disease. Alongside this new nursing specialisms are developing and the role of other health professionals, notably opticians and pharmacists, are being reassessed. ${ }^{34}$

However, the policy spotlight has, of course, been directed with increasing strength at GP fundholding as the major engine for change. More so now with the publication of the Executive Letter $E L(94) 79 .{ }^{35}$ This signalled the extension of total fundholding on a pilot basis. The initial models of fundholding seem to have shaken up the more neglected aspects of secondary care. Waiting lists and times for elective surgery, in particular, seem to have been significantly improved by fundholders. New ways of meeting the need for specialist care are being developed, including, for example, specialist outreach clinics and direct access services and new services such as counselling, physiotherapy, and complementary therapies are being offered within practices. ${ }^{36}$

On the other side of the balance sheet, however, it is now clear that GP fundholding has created a two tier system of access, particularly for elective surgery. ${ }^{37}$ While we must not discount these gains it is not clear how they can be spread over the whole population. Similarly, many of the innovations introduced have not been evaluated in terms of effectiveness, efficiency, or appropriateness. Of more importance, from my perspective, it is not self evidently the case that GP fundholding (total or otherwise) will be an effective means of producing a primary care led NHS. We have here a good example of the confusion that Titmuss warned about. What some hope will one day exist (a primary care led NHS) is suddenly thought by many to exist already in the guise of total fundholding. There are good reasons to be cautious about the prospects. I want to ask three questions in particular. Are the views of GPs an acceptable proxy for the needs of their practice populations? How will GPs manage their purchaser and provider roles and will one of the two roles inevitably suffer? How will GP fundholders manage the complex relationships with community health service staff and local authority staff? 


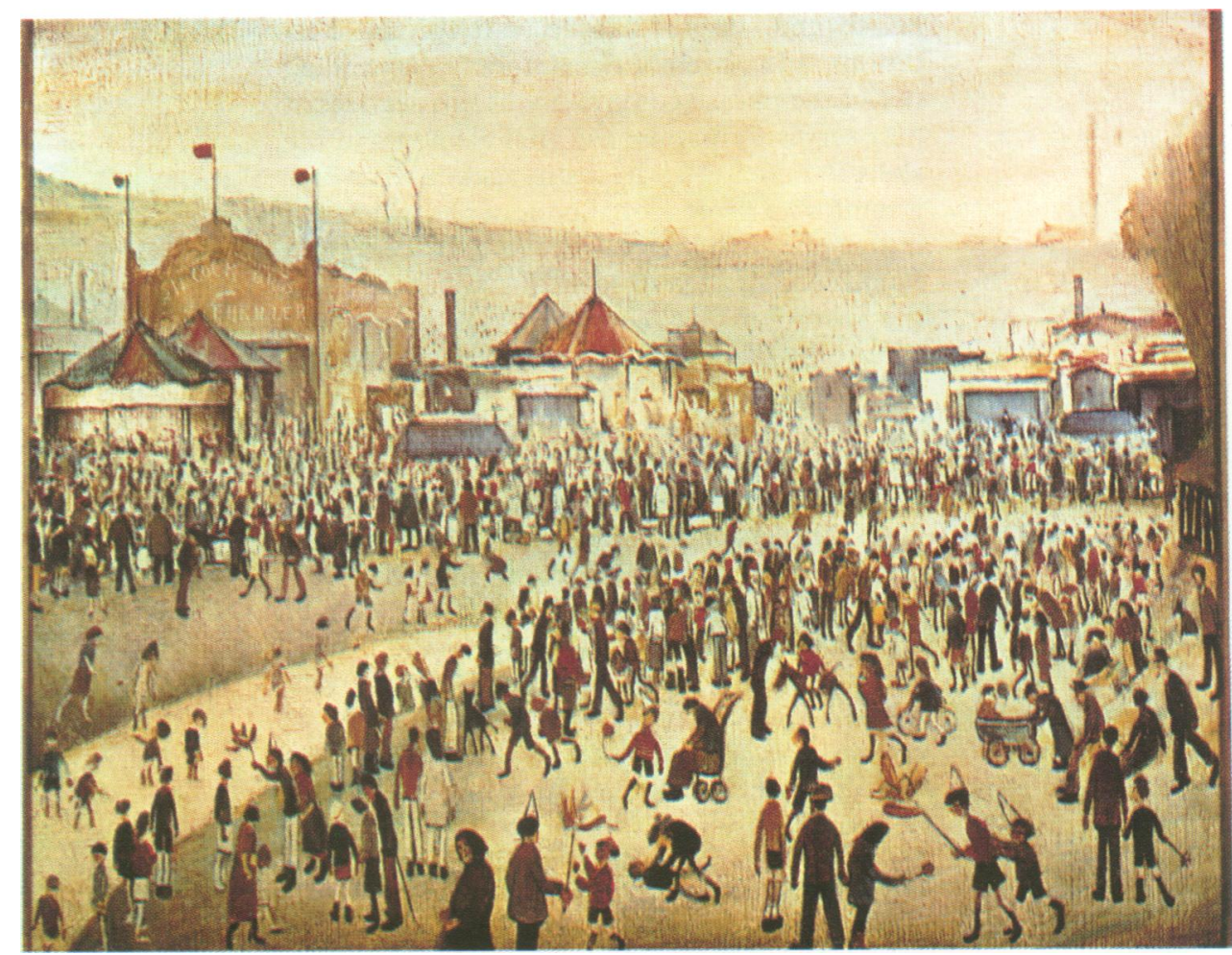

Two brief examples will have to serve to illuminate the possible difficulties here. The first relates to a potential divergence between a focus on acute illness and hospital care and the health needs of practice populations. In the early 1990s surveys of GPs by purchasing authorities showed that they place the need for speedy access to ophthalmology services high on their agenda, particularly for cataract removals. This has been the focus of a considerable amount of GP fundholder activity. While published studies show that cataracts are a major source of visual impairment, the main cause of visual disability in the elderly is age related maculopathy, a chronic degenerative condition for which there is no effective treatment. The extent of disability resulting from a vision problem like maculopathy is linked to a number of social and environmental factors, such as poor lighting in the home, lack of access to vision aids, ability to seek help, and financial circumstances. In a recent survey we found that while over $80 \%$ of older people who reported vision problems had been to their GP in the previous year, contact with other services was low - only $10 \%$ used any of a list of vision aids and under registration as partially sighted or blind was high. ${ }^{38}$ This is an important means of accessing other help and support. To date the evidence suggests that GPs are more likely to focus "downstream" on access to secondary care and the treatment of acute illness, to the neglect of a wider population perspective on health needs.

A similar story might be told in relation to mental illness. While GPs focus on the needs of the severely mentally ill, they continue to underdiagnose and, arguably, inappropriately treat depression - a high prevalence condition which, some evidence suggests, can if left become chronic and more severe.

Recent work on fundholding in Scotland also suggests that groups of patients not given priority through GP contract and not in need of secondary care, for example, people with musculoskeletal conditions or with social problems, may be getting a poorer quality service than others. ${ }^{39}$

Finally, the impact of total fundholding and the development of community fundholding on relationships between general practice, community health services, local authority social services, and the voluntary sector remains to be fully documented and is an important issue for the proposed evaluation of the new total fundholding pilot sites.

\section{Conclusions}

So to my final comments: I will resort to a Lowry painting - The fair ground. The link with my lecture may seem tenuous, but there is a sense in which health care systems in recent years have come close to this - swings, roundabouts, and most fun of all the helter skelter. Perhaps fewer smiling faces, but I continue to be surprised by the resilience of the health professionals and managers I work with. In this context I have been somewhat hesitant to talk about confusion and complacency, but as I have argued despite all the changes in recent years (or perhaps in part because of them) there remain areas within the field broadly defined as community health where greater clarity is needed.

First, I have pointed to the dangers of relying on the romanticised notion of community health to describe a terrain where positive action is required to reduce inequalities in 
health and support people with chronic conditions and disabilities. Similarly, continued use of the phrase community health services at best serves to marginalise vital elements of the skills required to address this agenda. At worse it reinforces professional boundaries which can mitigate against high quality care. It seems that Pat Gordon's idea of identifying and agreeing the distinguishing characteristics of primary care to be pursued at a local level may offer a way beyond these difficulties.

I have suggested that there is a need for greater clarity about the task facing those concerned with public health and primary care. The social care agenda is already gaining a higher profile. It is important that this continues. Of equal importance is the need to refocus services to reduce inequalities in health, concentrating particularly on targeting, accessibility, and appropriateness. There is, of course, the thorny question of who defines appropriateness. Here, I have suggested that health professionals will gain much if they can learn to value more highly the knowledge of lay people.

Finally, I have suggested that there is a need for greater clarity about the nature and purpose of a primary care led NHS. We should not be distracted by GP fundholding; it may have a contribution to make but it is probably neither a necessary nor a sufficient condition. I would suggest that in pursuit of a primary care-led service four recent developments need to be nurtured.

Firstly, there is the potential contribution of the experiments in strategic planning being pioneered by some health authorities. These are presently threatening to whither on the vine as the agenda facing health authorities gets refocused "downstream" in response to pressure from the centre. The fruits of population based health needs assessment at its best demonstrate the potential for the development of a balance of prevention, treatment, and care that is appropriate to need (clinically and lay defined), as well as efficient and effective.

Secondly, there is a growing confidence among many of those involved in primary care as they develop the home care/support agenda. This must be nurtured.

Thirdly, there are some good examples of greater equity among health and social care professionals in primary care in the pursuit of a common aim. Here, the GP works as an equal but different member of a team of practitioners providing care for the practice population. In these models equal attention is given to prevention, the treatment of disease, and the management of chronic illness, with the community health services providing complementary care across practices. Fundholding must not be allowed to eclipse these developments.

Fourthly, and finally, it is evident that lay people are being given more status within the service. Let us not be afraid to see this development through to its ultimate conclusion in terms of sharing power and control to the advantage of all.
1 Titmuss R. Community care: fact or fiction? In: Titmuss R. Commitment to welfare. London: Allen \& Unwin, 1961. Scott J. Poverty and wealth: citizenship, deprivation and privScott J. Poverty and wealth: citizenshi
ilege. London: Longman. 1994.

3 Ungerson C. Policy is personal: sex, gender and informal care. London: Tavistock, 1987

4 Gordon P. Viewpoint: the future of primary care. In: Ham $\mathrm{C}$ ed. 1994/95 NHS Handbook. National Association of Health Authorities and Trusts, 9th ed. Tunbridge Wells JHH Publishing, 1994.

5 Titmuss R. Commitment to welfare. London: Allen \& Unwin, $1961 ; 104$.

6 McKeown T. The modern rise of population. London: Edward Arnold, 1976

7 Webster C. The Victorian public health legacy: A challenge to the future. Birmingham: The Public Health Alliance, 1990.

8 Darbyshire J. Tuberculosis: old reasons for a new increase. BMF 1995;310:954-5.

9 Brown P. The return of the big killer. New Scientist 1992, October 10;32.

10 Martin J, Meltzer H, Elliot D. OPCS surveys of disability in Great Britain. Report 1. The prevalence of disability amongs adults. London: HMSO, 1988.

11 Department of Health and Social Security. Inequalities in health: Report of a research working group. London: DHSS 1980.

12 Townsend P, Davidson N. Inequalities in health: the Black report. 2nd ed. Harmondsworth: Penguin, 1988.

13 Office of Population Censuses and Surveys. Occupational mortality: The Registrar General's decennial supplement for Great Britain, 1979-80, 1982-83: Part 1 Commentary. OPCS Series DS No 6. London: HMSO, 1986.

14 Goldblatt P. Longitudinal study: mortality and social or ganisation 1971-1981. OPCS Series LS No 6. London: HMSO, 1990.

15 Office of Population Censuses and Surveys. Mortality stat istics; perinatal and infant: social and biological factors, Review of the Registrar General on deaths in England and Wales 1990. OPCS Series DH3 No 24, London: HMSO, 1992

16 Office of Population Census and Surveys. Occupational mortality: childhood supplement, The Registrar General's decennial supplement for England and Wales 1979-80, 1982-83. OPCS Series DS No 8, London: HMSO, 1988.

17 Data reported in society and health. Vol 1. London: The King's Fund Institute, 1994; 2.

18 McCormick A, Rosenbaum M. Morbidity statistics from gen eral practice; Third national study: socio-economic analysis,
OPCS Series MS5 No 2 London: HMSO, 1990 .

19 Davey-Smith G, Bartley M, Blane D. The Black report on socio-economic inequalities in health 10 years on. $B M$ 1990;301:373-7.

20 Blane D, Davey-Smith G, Bartley M. Social class differences in years of potential life lost: size, trends and principal causes. BMf 1990;301:429-32.

21 Phillimore $\mathrm{P}$, Beattie A, Townsend P. Widening inequalitie of health in northern England, 1981-91. BMF 1994;308 1125-8.

22 Wilkinson R. Unfair shares. London: Barnardos, 1994;4.

23 Benzeval $M$, Judge $\mathrm{K}$. Whitehead $\mathrm{M}$. Tackling inequalities in health: An agenda for action. London: King's Fund, 1995

24 Blackburn C, Graham H. Smoking amongst working clas mothers. An information pack. Coventry: University of Warwick.

25 Stathclyde Poverty Alliance. Communities against poverty: a resource pack. Glasgow: Strathclyde Regional Council.

26 Laughlin S, Black D. Poverty and health: tools for change. Ideas, analysis, information, action. York: Public Health Alliance/Joseph Rowntree Foundation, 1995.

27 Graham H. Women's smoking and family health. Soc Sci Med 1987;27:47-56.

28 Whitehead $M$. Tackling inequalities: a review of policy initiative. In: Benzeval $M$, Judge $K$, Whithead $M$. eds. Tackling inequalities in health: an agenda for action. London: King's Fund, 1995;22.

29 Popay J, Williams G. Public health research and lay knowledge. Soc Sci Med 1995;35:(in press).

30 Williams G, Popay J. Lay knowledge and the priviledge of experience. In: Gabe J, Kelleher D, Williams G. eds. experience. In: Gabe J, Kelleher D, Williams

31 Platt S, Martin C, Hunt S, Lewis C. Damp housing, mould growth and symptomatic health state. BMF 1989;298: $1673-8$

32 Kaplan GA, Kotler RL. Self reports: predictive of mortality. fournal of Chronic Diseases 1985;38:195-201.

33 Gordon P. Viewpoint: the future of primary care. In: Ham C ed. 1994/95 NHS handbook. 9th ed. National Association of Health Authorities and Trusts, 1994;23.

34 Taylor D. Developing primary care: opportunities for the 1990 London: King's Fund/Nuffield Provincial Hospitals Trust, 1991

35 NHS Executive 1994. Developing NHS purchasing and GP fundholding. EL(94)79. Leeds: NHS Executive, 20 October 1994.

36 Glennerster $\mathrm{H}$, Matsaganis M, Owens P, Hancock S. Im plementing GP fundholding: wild card or winning hand. Milton Keynes: Open University Press, 1994

37 Robinson R, Le Grand J eds. Evaluating the NHS reforms. London: King's Fund Institute, 1994.

38 Harries U, Landes R, Popay J. Visual disability among older people: a course study in assessing needs and examining people: a course study in assessing needs and ex.

39 Howie J. Heaney D, Maxwell M. General practice fundholding: shadow project - an evaluation. Edinburgh: Uniholding: shadow project - an evaluation. Edinburgh: University of Edin 1995. 